\title{
The effects of low and high doses of sugammadex on kidney tissue in streptozotocin-induced diabetic rats
}

\author{
Kip $\mathrm{G}^{1}$, Turgut $\mathrm{HC}^{2}$, Alkan $\mathrm{M}^{3}$, Aydin $\mathrm{ME}^{3}$, Erbatur $\mathrm{ME}^{3}$, Kiraz $\mathrm{HA}^{4}$, Kartal $\mathrm{S}^{5}$, Boyunaga $\mathrm{H}^{6}$, \\ Comu $\mathrm{FM}^{7}$, Erdem $\mathrm{O}^{8}$, Arslan $\mathrm{M}^{3}$, Unal $\mathrm{Y}^{3}$ \\ Gazi University Medical Faculty, Department of Anesthesiology and Reanimation , 06510 Ankara, Turkey. \\ marslan36@yahoo.com
}

\begin{abstract}
BACKGROUND: Sugammadex is primarily excreted via renal route. We investigated effects of low and high doses of sugammadex (16 mg/kg versus $96 \mathrm{mg} / \mathrm{kg}$ ) on renal tissue samples of streptozotocin-induced diabetic rats. MATERIAL AND METHODS: Twenty-four Wistar albino rats were divided into 4 groups. Group C (control -0.9 $\% \mathrm{NaCl}$ ), Group DC (diabetes control; $55 \mathrm{mg} / \mathrm{kg}$ streptozotocin, IP, only), Group DR-16S (diabetes-rocuronium - 16 mg sugammadex, IV.) and Group DR-96S (diabetes- rocuronium - 96 mg sugammadex, IV). Renal tissue histopathological evaluation and antioxidant status (measurements of MDA levels and NO activities) were studied. RESULTS: Significantly higher levels of all inflammation parameters (inflammation, degeneration/necrosis, tubular dilatation, tubular cell degeneration, dilatation in Bowman's space, tubular hyaline casts, and lymphocyte infiltration) were found in the $96 \mathrm{mg} / \mathrm{kg}$ sugammadex group. Higher MDA tissue levels and lower NO activity were found in the $96 \mathrm{mg} / \mathrm{kg}$ sugammadex group.

DISCUSSION: We can conclude that high-dose $(96 \mathrm{mg} / \mathrm{kg}$ ) sugammadex administration resulted in significant renal tissue damage in diabetic rats. As a consequence, low doses of sugammadex have to be preferred in diabetic patients (Tab. 2, Fig. 4, Ref. 26). Text in PDF www.elis.sk.

KEY WORDS: sugammadex, streptozotocin, diabetes, renal damage.
\end{abstract}

\section{Introduction}

Sugammadex is a unique $\gamma$-cyclodextrin designed to encapsulate, bind, and inactivate aminosteroidal non-depolarizing muscle relaxant agents such as rocuronium which has an extremely high affinity, vecuronium and pancuronium (1). Cyclodextrins (CD) are cyclic oligosaccharides that are used for increasing the water solubility of lipophilic molecules such as steroids, propofol, etomidate, antibiotics, and anti-cancer agents (2). Sugammadex is the first cyclodextrin that has been produced as a sole drug without adjuvant (3). Sugammadex is primarily ( $>90 \%$ ) excreted in the urine in an unchanged state within 48 hours after intravenous administration $(4,5)$. In patients with renal failure, sugammadex clearance is decreased while half-life and volume of distribution are increased (6).

${ }^{1}$ Gazi University Faculty of Dentistry, Department of Pediatric Dentistry, ${ }^{2}$ Gazi University Faculty of Dentistry, Department of Oral and Maxillofacial Surgery, ${ }^{3}$ Gazi University School of Medicine, Department of Anesthesiology and Reanimation, ${ }^{4}$ Canakkale Onsekiz Mart University School of Medicine, Department of Anesthesiology and Reanimation, ${ }^{5}$ Turgut Ozal University School of Medicine, Department of Anesthesiology and Reanimation, ${ }^{6}$ Kirikkale University School of Medicine, Department of Biochemistry, ${ }^{7}$ Kirikkale University School of Medicine, Department of Physiology, and ${ }^{8}$ Gazi University School of Medicine, Department of Pathology

Address for correspondence: M. Arslan, Dr, Gazi University Medical Faculty, Department of Anesthesiology and Reanimation, 06510 Ankara, Turkey

Phone: +90.312 .2026739$
Diabetic nephropathy is characterized with microalbuminuria (persistent albuminuria at level of 30-299 mg/24 hours) followed by macroalbuminuria (persistent albuminuria at level of $300 \mathrm{mg} / 24$ hours) in advanced disease. Macroalbuminuria is often diagnosed after many years in type 1 diabetes but an early diagnosis is more prominent in type 2 diabetes. Macroalbuminuria has a key role in developing end-stage renal disease (ESRD). The natural history depends on the type of diabetes. In untreated course of type 1 diabetes, there is an elevated risk of ESRD development in $50 \%$ of patients within 10 years, and by 20 years the incidence increases up to $75 \%$ (17). In type 2 diabetes, the risk of ESRD development is about $4-8 \%(7,17,19)$.

Sugammadex is excreted in an unchanged state and does not affect blood sugar levels (8), however there is no study investigating sugammadex effects on diabetics and diabetic nephropathy. In this study, we investigated the effects of low versus high doses of sugammadex (16 and $96 \mathrm{mg} / \mathrm{kg}$ ) on renal tissue of rats with streptozotocin-induced diabetes.

\section{Material and methods}

This study was conducted in the GUDAM Laboratory of Gazi University with the consent of the Experimental Animals Ethics Committee of Gazi University. All the procedures were performed according to the accepted standards of the Guide for the Care and Use of Laboratory Animals.

In the study, 24 male Wistar albino rats weighing between 
225 and $300 \mathrm{~g}$, raised under the same environmental conditions, were used. For at least one week prior to surgery, the animals were housed in standard cages in a pathogen-free environment with free access to food (until $2 \mathrm{~h}$ before the anesthetic procedure) and water and with a 12-hour light/dark cycle. The animals were randomly separated into four groups, each containing six rats.

Diabetes was induced by a single IP injection of streptozotocin (Sigma Chemical, St. Louis, MO, USA) at a dose of $55 \mathrm{mg} / \mathrm{kg}$ body weight. The blood glucose levels were measured $72 \mathrm{~h}$ after this injection. The rats were classified as diabetic if their fasting blood glucose (FBG) levels exceeded $250 \mathrm{mg} / \mathrm{dl}$, and only the animals with FBG levels $>250 \mathrm{mg} / \mathrm{dl}$ were included in the diabetic groups. The rats were kept alive for four weeks after streptozotocin injection to allow the development of chronic diabetes (18).

At the end of a thirty-day period, $100 \mathrm{mg} / \mathrm{kg}$ ketamine was administered intraperitoneally. Tracheostomy was performed in all animals in the supine position via $12 \mathrm{G}$ cannula, and intubation was performed in all animals. The esophagus of animals was strictly protected while performing tracheostomy. Intubation cannula was fixed carefully. Ventilation was maintained by means of room-air ventilator machine. The rate was $70-100 / \mathrm{min}$, tidal volume was 2.5-3 $\mathrm{ml}$, and PEEP was $2 \mathrm{mmHg}$.

There were four experimental groups: Group C (control; $\mathrm{n}=$ 6), Group DC (diabetes control; $n=6$ ), Group DR-16S (diabetesrocuronium-16mg sugammadex; $\mathrm{n}=6$ ) and Group DR-96S (diabetes-rocuronium - $96 \mathrm{mg}$ sugammadex; $n=6$ ). Rats in DR-16S and DR-96S groups received a single intravenous dose of 16 or 96 $\mathrm{mg} / \mathrm{kg}$ of sugammadex, respectively. Rats in control and diabetes groups received the same volume of $0.9 \% \mathrm{NaCl}$. Following the reversal of muscle relexant effect of rocuronium, the rats were allowed to breathe spontaneously.

Anesthesia was maintained by repetitive injections of $20 \mathrm{mg} /$ $\mathrm{kg}$ ketamine if a positive reaction to surgical stress or intermittent tail pinch could be observed.

\section{Histopathological evaluation of the kidney}

They were then examined with light microscopy by the same pathologist who was blinded to the study. Ten random areas were evaluated with $400 \mathrm{x}$ magnified microscopy in H\&E stained sec- tions. Kidney injury in each area was examined by evaluating the inflammation, degeneration/necrosis, tubular dilatation, tubular cell degeneration, dilatation in Bowman's space, tubular hyaline casts, and lymphocyte infiltration in the kidney tissue. Each parameter was evaluated as none, slight, moderate, or severe; two scores were added, and the total score was interpreted as the kidney injury score.

\section{Measurements of MDA levels and NO activities}

Esterbauer method was applied in order to measure lipid peroxidation. Malondialdehyde reacted with thiobarbituric acid at 90-95 ${ }^{\circ} \mathrm{C}$ and resulted in pink chromogranin. After 15 minutes, specimens were rapidly cooled and absorbances were read at 532 $\mathrm{nm}$ spectrophotometrically. Results were represented as nmol/g tissue protein (19). Concentrations of stable oxidative metabolites of $\mathrm{NO}\left(\mathrm{NO}_{2}-\mathrm{vs} \mathrm{NO}_{3}-\right)$ were measured in serum and $\mathrm{NO}$ production was determined. Measurement of nitrite concentration was performed with Griess reaction (20).

\section{Statistical analyses}

Statistical Package for the Social Sciences (version 20.0, SPSS, Chicago, IL, USA) was used for statistical analysis. The Kolmogorov-Smirnov test was used for the comparisons to determine the distribution of all variable groups. Variations in NO activities and MDA levels, and histopathological parameters were assessed by using the Kruskal-Wallis test. Bonferroni-adjusted Mann-Whitney U test was used after significant Kruskal-Wallis to determine which group differs from the other. Results were expressed as mean \pm standard deviation (Mean $\pm \mathrm{SD}$ ). Statistical significance was set at a $\mathrm{p}$ value $<0.05$.

\section{Results}

When the groups with kidney tissue inflammation verified by light microscopic findings were compared to each other, a significant difference was observed among the groups $(p<0.0001)$. The inflammation score was found to be significantly higher in the 96S group compared to C, DC and $16 \mathrm{~S}$ groups $(\mathrm{p}=0.001, \mathrm{p}=0.018$, respectively) (Tab. 1) (Figs 1-4). Additionally, the inflammation

Tab. 1. Histopathological findings in the kidney tissue (mean \pm SEM)).

\begin{tabular}{|c|c|c|c|c|c|}
\hline & Group C $(n=6)$ & Group DC $(n=6)$ & Group $16 \mathrm{~S}(\mathrm{n}=6)$ & Group $96 \mathrm{~S}(\mathrm{n}=6)$ & $\mathrm{p}^{* *}$ \\
\hline Inflammation & $0.0 \pm 0.0 *$ & $0.67 \pm 0.33 *$ & $0.83 \pm 0.31 * \&$ & $2.33 \pm 0.33$ & $<0.0001$ \\
\hline Degeneration/ necrosis & $0.0 \pm 0.0 *$ & $0.67 \pm 0.21 * \&$ & $0.67 \pm 0.21 * \&$ & $1.83 \pm 0.31$ & $<0.0001$ \\
\hline Tubular dilatation & $0.0 \pm 0.0 *$ & $1.33 \pm 0.21 * \&$ & $1.50 \pm 0.22^{\&}$ & $2.00 \pm 0.26$ & $<0.0001$ \\
\hline Tubular cell degeneration & $0.33 \pm 0.21 *$ & $1.00 \pm 0.37 *$ & $1.33 \pm 0.33 * \&$ & $2.33 \pm 0.33$ & 0.002 \\
\hline Dilatation in Bowman's space & $0.0 \pm 0.0 *$ & $0.83 \pm 0.31 * \&$ & $0.83 \pm 0.31 * \&$ & $2.17 \pm 0.17$ & $<0.0001$ \\
\hline Tubular hyaline casts & $0.17 \pm 0.17^{*}$ & $0.83 \pm 0.31 *$ & $0.83 \pm 0.31 *$ & $2.33 \pm 0.42$ & 0.001 \\
\hline Lymphocyte infiltration & $0.0 \pm 0.0 *$ & $0.83 \pm 0.31 * \&$ & $1.00 \pm 0.37 * \&$ & $2.66 \pm 0.21$ & $<0.0001$ \\
\hline
\end{tabular}

$\mathrm{p}^{* *}$ : Statistical significance was set at a $\mathrm{p}$ value $<0.05$ for Kruskal-Wallis test, * $\mathrm{p}<0.05$ : When compared with Group $96 \mathrm{~S},{ }^{\&} \mathrm{p}<0.05$ : When compared with Group C

Tab. 2. Oxidant status parameters in rat kidney tissue (mean $\pm \mathrm{SEM})$.

\begin{tabular}{|c|c|c|c|c|c|}
\hline & Group $C(n=6)$ & Group DC $(n=6)$ & Group 16S $(n=6)$ & Group 96S $(n=6)$ & $\mathrm{p}^{* *}$ \\
\hline MDA (nmol/mg prot) & $6.49 \pm 0.78 *$ & $16.64 \pm 2.49^{* \&}$ & $17.77 \pm 2.21 * \&$ & $28.48 \pm 4.04$ & 0.001 \\
\hline NO (IU/mg prot) & $11.15 \pm 1.50 *$ & $5.02 \pm 1.00 * \&$ & $4.39 \pm 0.91^{\&}$ & $2.43 \pm 0.74$ & 0.003 \\
\hline
\end{tabular}




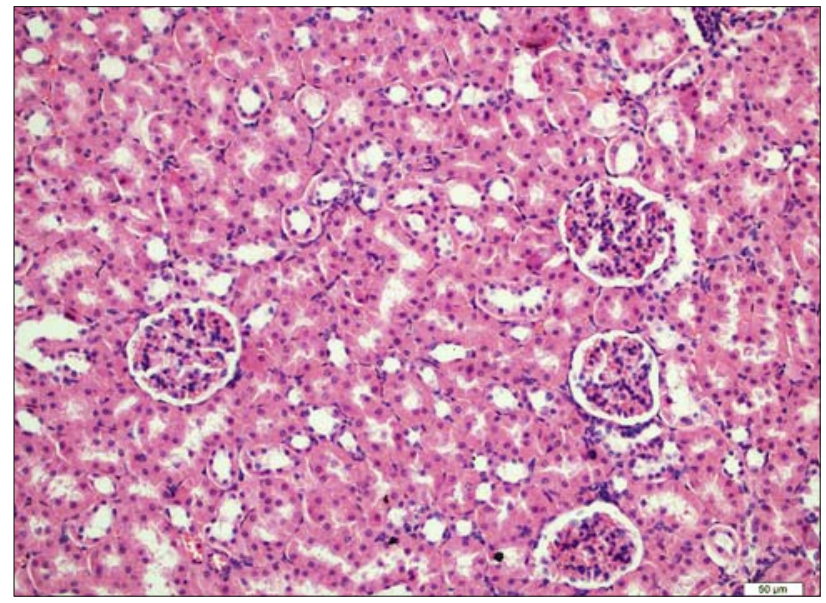

Fig. 1. Normal structure of kidney tissue in the control group, HE x100.

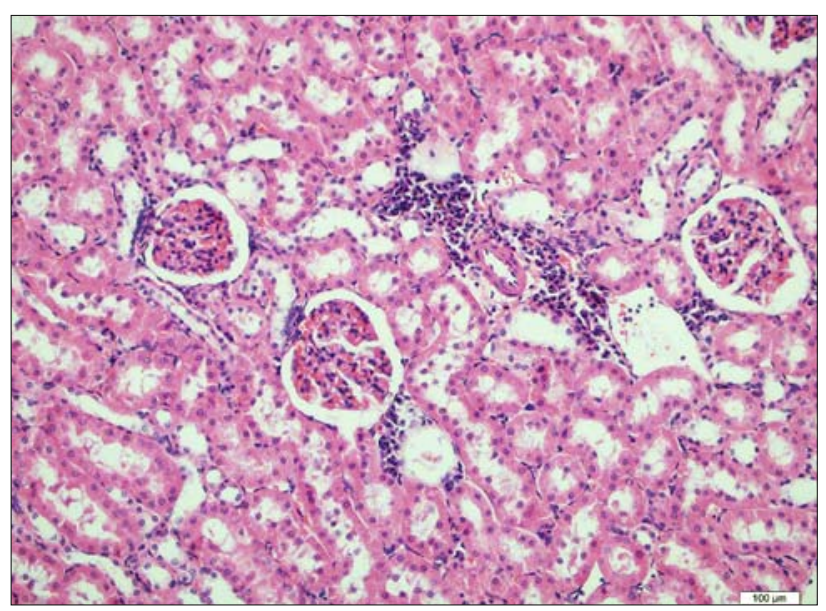

Fig. 2. Tubular cell degeneration in the kidney tissue in the diabetic control group, HE x200.

score was found to be significantly higher in the $16 \mathrm{~S}$ group compared to the $\mathrm{C}$ group $(\mathrm{p}=0.003)$.

Degeneration/necrosis score in kidney tissue was found to be significantly higher in the $96 \mathrm{~S}$ group compared to C, DC and $16 \mathrm{~S}$ groups $(\mathrm{p}=0.003, \mathrm{p}=0.003, \mathrm{p}=0.016$, respectively) (Tab. 1) (Figs 1-4). Additionally, the degeneration/necrosis score was found to be significantly higher in the DC and $16 \mathrm{~S}$ groups compared to the C group ( $p=0.003, p=0.007$, respectively).

The tubular dilatation score in kidney tissue was found to be significantly higher in the $96 \mathrm{~S}$ group compared to C, DC and $16 \mathrm{~S}$ groups ( $p=0.003, p=0.003, p=0.016$, respectively) (Tab. 1) (Figs 1-4). Additionally, the tubular dilatation score was found to be significantly higher in the $\mathrm{DC}$ and $16 \mathrm{~S}$ groups compared to the $\mathrm{C}$ group ( $\mathrm{p}=0.003, \mathrm{p}=0.007$, respectively).

When the groups were compared to each other for kidney tissue tubular cell degeneration determined with light microscope, a significant difference was observed among the groups $(\mathrm{p}<0.0001)$. The tubular cell degeneration score was found to be significantly higher in the $96 \mathrm{~S}$ group compared to $\mathrm{C}, \mathrm{DC}$ and $16 \mathrm{~S}$ groups ( $\mathrm{p}=$ $0.001, p=0.018$ respectively) (Tab. 1) (Figs 1-4). Additionally,

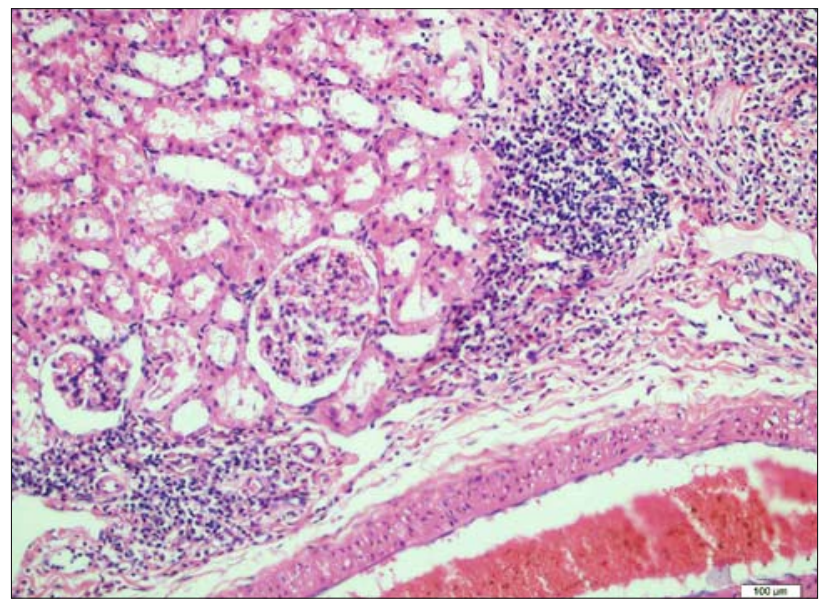

Fig. 3. Mild Tubular dilatation and lymphocyte infiltration in the diabetes-rocuronium - 16 mg sugammadex group, HE x100.

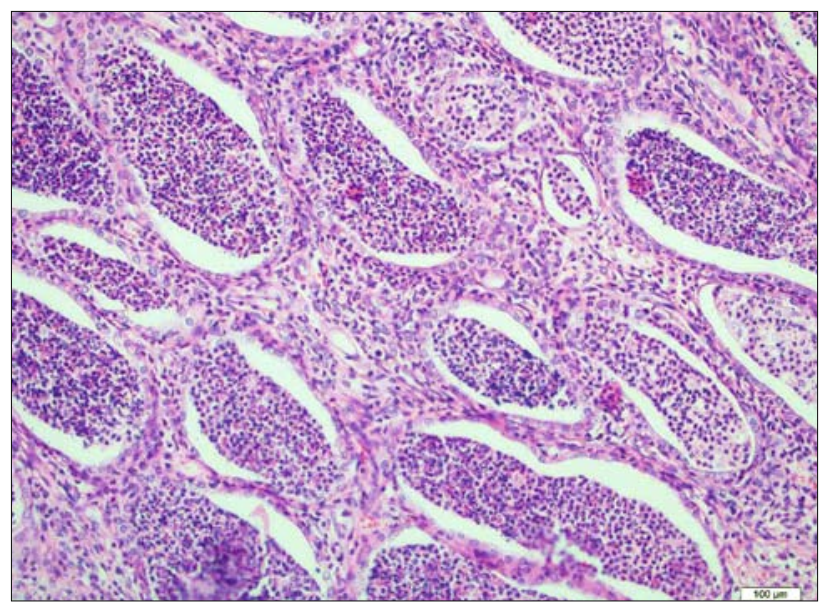

Fig. 4. Extensive Inflammation and lymphocyte infiltration in the diabetes-rocuronium - 96 mg sugammadex group, HE x200.

the tubular cell degeneration score was found to be significantly higher in the $16 \mathrm{~S}$ group compared to the $\mathrm{C}$ group $(\mathrm{p}=0.003)$.

The score of dilatation in Bowman's space in kidney tissue was found to be significantly higher in the $96 \mathrm{~S}$ group compared to $\mathrm{C}$, DC and $16 \mathrm{~S}$ groups $(\mathrm{p}=0.003, \mathrm{p}=0.003, \mathrm{p}=0.016$, respectively) (Tab. 1) (Figs 1-4). Additionally, the score of dilatation in Bowman's space was found to be significantly higher in the DC and $16 \mathrm{~S}$ groups compared to the $\mathrm{C}$ group $(\mathrm{p}=0.003, \mathrm{p}=0.007$, respectively).

The score of tubular hyaline casts in kidney tissue was found to be significantly higher in the $96 \mathrm{~S}$ group compared to C, DC and $16 \mathrm{~S}$ groups $(p=0.003, p=0.003, p=0.016$, respectively) $($ Tab. 1$)$ (Figs 1-4).

When the groups with kidney tissue lymphocyte infiltration assessed by light microscopic findings were compared, a significant difference was observed among the groups $(p<0.0001)$. The kidney tissue lymphocyte infiltration score was found significantly higher in the $96 \mathrm{~S}$ group compared to $\mathrm{C}, \mathrm{DC}$ and $16 \mathrm{~S}$ groups ( $\mathrm{p}=$ $0.003, p=0.003, p=0.008$, respectively) (Tab. 1) (Figs 1-4). Additionally, lymphocyte infiltration score was found to be significantly higher in the DC and $16 \mathrm{~S}$ groups compared to the $\mathrm{C}$ group ( $p=0.003, p=0.007$, respectively). 
When groups were compared to each other for plasma MDA levels, a significant difference was observed $(p=0.001)$. MDA level was found to be significantly higher in the $96 \mathrm{~S}$ group compared to the $\mathrm{C}, \mathrm{DC}$ and $16 \mathrm{~S}$ groups ( $\mathrm{p}=0.005, \mathrm{p}=0.002$, respectively) (Tab. 2). Additionally, MDA levels were found to be significantly higher in the $\mathrm{DC}$ and $16 \mathrm{~S}$ groups compared to the $\mathrm{C}$ group $(\mathrm{p}=$ $0.003, \mathrm{p}=0.007$, respectively).

When the groups were compared to each other for plasma NO enzyme activity, a significant difference was observed $(p=0.003)$. NO enzyme activity was found to be significantly higher in the 96S group compared to the $\mathrm{C}, \mathrm{DC}$ and $16 \mathrm{~S}$ groups $(\mathrm{p}=0.002, \mathrm{p}$ $=0.012$, respectively) (Tab. 2). Additionally, NO enzyme activity was found to be significantly higher in the DC and $16 \mathrm{~S}$ groups compared to the $\mathrm{C}$ group $(\mathrm{p}=0.003, \mathrm{p}=0.007$, respectively).

\section{Discussion}

Sugammadex is a modified gamma CD that encapsulates NMBA molecules in plasma, prevents NMBA-Ach receptor binding, and rapidly reverses the attached NMBA molecules to plasma via osmotic gradient difference and as a consequence, rapid resolution of muscle relaxant effects of NMBA molecules occurs (9). Reversal effect of sugammadex for rocuronium is significantly more prominent than vecuronium and pancuronium (10-12). Sugammadex is a highly water-soluble molecule and both sugammadex and its complex with rocuronium are excreted renally. Renal elimination of sugammadex is linear with glomerular filtration rate (8). Rocuronium is primarily excreted in bile and feces and only $33 \%$ of rocuronium when administered $1 \mathrm{mg} / \mathrm{kg}$ is excreted via the kidneys. However elimination of rocuronium is shifted to the renal route when sugammadex is administered and the amount of rocuronium renally eliminated is correlated with the sugammadex dose. Plasma clerance of the sugammadex-rocuronium complex is similar to that of sugammadex (13). Following $4-8 \mathrm{mg} / \mathrm{kg} \mathrm{su}-$ gammadex treatment, the excretion of rocuronium in the urine increases up to $58-74 \%$ (normally this ratio is about $26 \%$; 14 ).

\section{Sugammadex and postoperative renal adverse events}

Like other cyclodextrins, sugammadex is a macromolecule ( $>$ 2000 dalton) and may lead to tubular toxicity via being collected and non-filtered through glomerules and tubules. Like with other cyclodestrines, in order to prevent such consequence, a single bolus dose of sugammadex is recommended. Also sugammadex is not recommended in patients with severe renal failure (creatinin clearence $<30 \mathrm{ml} / \mathrm{min} ; 15)$.

Sorgenfrei et al (8) postoperatively detected urine abnormalities including increased $\mathrm{N}$-acetylglucosaminidase in 6 patients and albumin in 1 patient. They concluded that these findings are insignificant and they were also detected in placebo group (8). Sparr et al (14) showed renal tubular and glomerular damage in 10 patients. They found increased microglobulin, $\mathrm{N}$-acetylglucosaminidase and $\beta 2$ microglobulin levels. However, they concluded that these findings were mild adverse events and independent from dose and administration time of sugammadex. In their study group (6 mg/ $\mathrm{kg}$ sugammadex), one patient had an increased serum creatinine level on postoperative day 1 . Elevated creatinine levels returned to normal levels on postoperative day 20 (14).

Pharmacokinetics of sugammadex alters in patients with renal failure. Volume of distribution, renal plasma clearance and half-life of sugammadex are significantly increased in this group of patients (15). In renal failure state, much longer elimination time of sugammadex plus rocuronium complex was found although Staals et al. could not show any level of recurarization after 48 hours of sugammadex administration (16). Additionally, the efficacy of sugammadex in patients with renal failure was found to be similar to that in inpatients with normal GFR and renal functions (6). For another special patient group, the elderly, there is no recommended sugammadex dose regulation. The clinical recovery after sugammadex administration in the elderly was similar to that in non-elderly (17).

Several studies have been investigated for renal adverse events of sugammadex up to $96 \mathrm{mg} / \mathrm{kg}$ (4) and unchanged renal function test results (blood urea, nitrogen, creatinine levels) with efficacy similar to that in placebo-control groups were reported. In contrast to previous studies we showed a sufficient safety profile with $16 \mathrm{mg} /$ $\mathrm{kg}$ sugammadex, however renal injury and increased inflammatory response were observed in the $96 \mathrm{mg} / \mathrm{kg}$ sugammadex group. There is only one study (18) that investigates renal histopathological changes in rats after different doses (16 versus $96 \mathrm{mg} / \mathrm{ml}$ ) of sugammadex. Bostan et al (18) showed histopathological damage in high-dose group $(96 \mathrm{mg} / \mathrm{kg}$ ) while blood urea, creatinine and electrolyte levels were similar to those in both control and low-dose group. Most of previous studies have investigated renal adverse events via RFT results or urine levels of several metabolites (such as albumin, $\mathrm{N}$ acetylglucosaminidase, etc.) while not comparing the histopathological changes. As a consequence all these studies might underestimate renal histopathological changes that could possibly lead to functional disturbances in the near future. Diabetic nephropathy is an excellent example of microscopic deterioration induced by renal functional failure. Mesangial expansion, thickened basal membranes, and nodularglomerulosclerosis (Kimmelstiel-Wilson nodules) are prominent features of glomerular disease. Tubular hypertrophy followed by interstitial fibrosis and arteriolar hyalinosis are important pathologic processes in renal tubules. In uncontrolled disease, infiltration with macrophages and T-lymphocytes complicates the process $(21,22)$. Following the histopathological changes in glomerular and tubular sections, glomerular hyperfiltration, and increased albumin excretion occur. Subsequently, if the pathologic process progresses to advanced disease, gross proteinuria and diminished GFR occur. Our findings show similar histopathological changes that can be seen in diabetic nephropathy including inflammation, degeneration, necrosis, tubular dilatation, tubular cell degeneration, dilatation in Bowman's space, tubular hyaline casts, and lymphocyte infiltration. However, we could find no significant difference in diabetic control versus $16 \mathrm{mg} / \mathrm{kg}$ sugammadex treatment group in terms of histopathological changes. So we can conclude that it was not the dose of $16 \mathrm{mg} / \mathrm{kg}$ of sugammadex, rather it was that of $96 \mathrm{mg} / \mathrm{kg}$ that resulted in significant renal tissue damage in diabetic rats. Bostan et al (18) showed similar findings in non-diabetic rats treated with $96 \mathrm{mg} / \mathrm{kg}$ sugammadex and concluded that elongated exposure of renal tissue to sugammadex-rocuronium complex might result in 
such pathologic changes. In contrast to histopathological findings they could find no abnormalities in blood urea and creatinine levels. We can again speculate that the determination of blood urea, creatinine and electrolyte levels at a single time point ( 72 hours after treatment) without much longer follow-up periods may lead to missing the detection of possible renal function losses that emerge due to ongoing pathological processes such as diabetic nephropathy.

We measured the plasma NO enzyme activity and plasma MDA levels in order to assess inflammatory response to therapy. We found an increased inflammatory response in both diabetic control and sugammadex groups. Interestingly the inflammatory response in the $96 \mathrm{mg} / \mathrm{kg}$ group was significantly higher than that in all study groups (Tab. 2). In diabetic nephropathy, the role of inflammatory pathways is clearly demonstrated. Oxidative stress and reactive oxygen species (ROS) damage DNA, RNA and other protein structures. In addition, these stressors activate cellular stress pathways like MAP-Kinase, Protein Kinase C and Nuclear factor kappa $\mathrm{B}(23,24)$. In turn, oxidative stress leads to increased NADH/NAD ratio which facilitates cell damage $(25,26)$. However in the high-dose sugammadex group, we found a response that was more prominent than that in diabetes group and low-dose sugammadex groups. These findings are supported by the histopathological findings and we speculate that the high dose of sugammadex alone or in complex with rocuronium may trigger inflammatory processes that damage the renal system. Finally we can suggest that if it is necessary to use a high dose of sugammadex in both diabetics and patients with no comorbidities, anti-inflammatory treatment choices may be kept in mind.

\section{References}

1. Bom A, Bradley M, Cameron K, Clark JK, Van Egmond J, Feilden H et al. A novel concept of reversing neuromuscular block: chemical encapsulation of rocuronium bromide by a cyclodextrin-based synthetic host. Angew Chem Int Ed Engl 2002; 41: 266-270.

2. Welliver M. Update for nurse anesthetists. Part 3. Cyclodextrin introduction to anesthesia practice: form, function, and application. AANA J 2007; 75: 289-296.

3. Welliver M, McDonough J, Kalynych N, Redfern R. Discovery, development, and clinical application of sugammadex sodium, a selective relaxant binding agent. Drug Design Develop Ther 2008; 2: 49-59.

4. Peeters PA, van den Heuvel MW, van Heumen E et al. Safety, tolerability and pharmacokinetics of sugammadex using single high doses (up to $96 \mathrm{mg} / \mathrm{kg}$ ) in healthy adult subjects: a randomized, double-blind, crossover, placebo-controlled, single-centre study. Clin Drug Investig 2010; 30: 867-874.

5. Peeters PA, Passier P, Smeets $\mathbf{J}$ et al. Sugammadex is cleared rapidly and primarily unchanged via renal excretion. Biopharm Drug Dispos 2011; 32: $159-167$.

6. Cammu G, Van Vlem B, van den Heuvel M, Stet L, el Galta R, Eloot S, Demeyer I. Dialysability of sugammadex and its complex with rocuronium in intensive care patients with severe renal impairment. Br J Anaesth 2012; 109 (3): 382-390.

7. Lim AKH. Diabetic nephropathy - complications and treatment. International Journal of Nephrology and Renovascular Disease 2014; 7: 361-381.

8. Sorgenfrei IF, Norrild K, Larsen PB et al. Reversal of rocuroniuminduced neuromuscular block by the selective relaxant binding agent sugammadex: a dose-finding and safety study. Anesthesiology 2006; 104: 667-674.
9. Epemolu O, Bom A, Hope F, Mason R. Reversal of neuromuscular blockade and simultaneous increase in plasma rocuronium concentration after the intravenous infusion of the novel reversal agent Org 25969. Anesthesiology 2003; 99: 632-637.

10. Alvarez-Gomez JA, Wattwil M, Vanacker B et al. Reversal of vecuronium-induced shallow neuromuscular blockade is signifi cantly faster with sugammadex compared with neostigmine. Eur J Anaesthesiol 2007; 24 (Suppl 39): 124-125.

11. Decoopman M, Cammu G, Suy K et al. Reversal of pancuroniuminduced block by the selective relaxany binding agent sugammadex. Eur J Anaesthesiol 2007; 24 (Suppl 39): 110-111.

12. Duvaldestin P, Kuizenga K, Saldien V, Claudius C, Servin F, Klein J et al. A randomized, dose-response study of sugammadex given for the reversal of deep rocuronium- or vecuronium-induced neuromuscular blockade under sevoflurane anesthesia. Anesth Analg 2010; 110: 74-82.

13. Staals LM, Snoeck MM, Driessen JJ et al. Reduced clearance of rocuronium and sugammadex in patients with severe to endstage renal failure: a pharmacokinetic study. Br J Anaesth 2010; 104: 31-39.

14. Sparr HJ, Vermeyen KM, Beaufort AM et al. Early reversal of profound rocuronium-induced neuromuscular blockade by sugammadex in a randomized multicenter study: efficacy, safety, and pharmacokinetics. Anesthesiology 2007; 106: 935-943.

15. Staals LM, Snoeck MM, Driessen JJ, Flockton EA, Heeringa M, Hunter JM. Multicentre, parallel-group, comparative trial evaluating the efficacy and safety of sugammadex in patients with endstage renal failure or normal renal function. Br J Anaesth 2008; 101: 492-497.

16. Staals LM, Snoeck MM, Driessen JJ et al. Reduced clearance of rocuronium and sugammadex in patients with severe to endstage renal failure: a pharmacokinetic study. Br J Anaesth 2010; 104: 31-39.

17. McDonagh DL, Benedict PE, Kovac AL et al. Efficacy and safety for reversal of rocuronium-induced blockade in elderly patients. Anesthesiology 2007; 107: A1583.

18. Bostan H, Kalkan Y, Tomak Y, Tumkaya L, Altuner D, Yılmaz A, Erdivanlı B, Bedir R. Reversal of Rocuronium-Induced Neuromuscular Block with Sugammadex and Resulting Histopathological Effects in Rat Kidneys Renal Failure, 2011; 33 (10): 1019-1024.

19. Esterbauer H, Cheeseman KH. Determination of aldehydic lipid peroxidation products: malonaldehyde and 4-hydroxynonenal. Methods Enzymol 1990; 186: 407-421.

20. Cortas NK, Wakid NW (1990). Determination of inorganic nitrate in serum ana urine by a kinetic cadmium-reduction method. Clin Chem 1990;36: 1440-1443.

21. Weil EJ, Lemley KV, Mason CC et al. Podocyte detachment and reduced glomerular capillary endothelial fenestration promote kidney disease in type 2 diabetic nephropathy. Kidney Int 2012; 82 (9): 1010-1017.

22. Toyoda M, Najafian B, Kim Y, Caramori ML, Mauer M. Podocyte detachment and reduced glomerular capillary endothelial fenestration in human type 1 diabetic nephropathy. Diabetes 2007; 56 (8): 2155-2160.

23. Haneda M, Araki S, Togawa M, Sugimoto T, Isono M, Kikkawa R. Mitogen-activated protein kinase cascade is activated in glomeruli of diabetic rats and glomerular mesangial cells cultured under high glucose conditions. Diabetes. 1997; 46 (5): 847-853.

24. Ha H, Lee HB. Reactive oxygen species as glucose signaling molecules in mesangial cells cultured under high glucose. Kidney Int Suppl 2000; 77: S19-S25.

25. Srivastava SK, Ramana KV, Bhatnagar A. Role of aldose reductase and oxidative damage in diabetes and the consequent potential for therapeutic options. Endocr Rev 2005; 26 (3): 380-392.

26. Williamson JR, Chang K, Frangos M et al. Hyperglycemic pseudohypoxia and diabetic complications. Diabetes 1993; 42 (6): 801-813.

Received March 10, 2015. Accepted May 28, 2015. 